\title{
Preventing Substance Use Among Indigenous Adolescents in the USA, Canada, Australia and New Zealand: a Systematic Review of the Literature
}

\author{
Mieke Snijder ${ }^{1}$ (D) Lexine Stapinski ${ }^{1} \cdot$ Briana Lees $^{1} \cdot$ James Ward $^{2} \cdot$ Patricia Conrod $^{3} \cdot$ Christopher Mushquash $^{4}$.

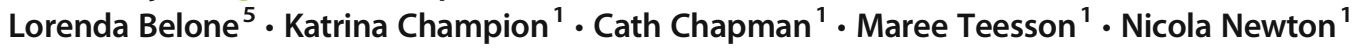

Published online: 22 October 2019

(C) The Author(s) 2019

\begin{abstract}
This systematic review assessed the current evidence base of substance use prevention programs for Indigenous adolescents in the USA, Canada, Australia and New Zealand. The authors investigated (a) the outcomes, type, setting and context of prevention programs; (b) the common components of beneficial prevention programs; and (c) the methodological quality of evaluations of included prevention programs. The authors searched eight peer-reviewed and 20 grey literature databases for studies published between 1 January 1990 and 31 August 2017. Data extracted included type of program (culturally adapted, culture-based or unadapted), the setting (school, community, family or multi-setting), delivery (computerised or traditional), context (Indigenousspecific or multi-cultural environment) and common components of the programs. Program evaluation methodologies were critically appraised against standardised criteria. This review identified 26 eligible studies. Substance use prevention programs for Indigenous youth led to reductions in substance use frequency and intention to use; improvements in substance-related knowledge, attitudes and resistance strategies; and delay in substance use initiation. Key elements of beneficial programs included substance use education, skills development, cultural knowledge enhancement and community involvement in program development. Five programs were rated as methodologically strong, seven were moderate and fourteen were weak. Prevention programs have the potential to reduce substance use among Indigenous adolescents, especially when they are developed in partnership with Indigenous people. However, more rigorously conducted evaluation trials are required to strengthen the evidence base.
\end{abstract}

Keywords Substance use $\cdot$ Prevention $\cdot$ Indigenous $\cdot$ Native $\cdot$ Aboriginal $\cdot$ Adolescent $\cdot$ Evaluation

\section{Introduction}

Indigenous peoples in the United States of America (USA), Canada, Australia and New Zealand have a comparable history

Mieke Snijder

mieke.snijder@sydney.edu.au

1 The Matilda Centre, Faculty of Health and Medicine, The University of Sydney, Darlington, Sydney, NSW 2006, Australia

2 South Australian Health and Medical Research Institute, Flinders University, Adelaide, Australia

3 Department of Psychiatry, Université de Montréal, Montreal, Canada

4 Centre for Rural and Northern Health Research, Northern Ontario School of Medicine, Lakehead University, Thunder Bay, Canada

5 Department of Health, Exercise \& Sports Sciences, College of Education, University of New Mexico, Albuquerque, NM, USA of colonisation and dispossession of culture and land by English settlers, resulting in predominantly English-speaking countries in which Indigenous People are a marginalised minority. The centuries following early colonisation have continued to harm Indigenous peoples through cultural genocide and forced assimilation attempts (e.g. residential schools and the 60s Scoop in Canada, and child removal policies leading to Stolen Generations in Australia). Some governments have officially acknowledged and apologised for their roles in the disruption and abuses inflicted upon Indigenous peoples (Coalition of Australian Governments 2009; Truth and Reconcilitation Commission 2015).

This history combined with contemporary issues such as continued policy failures in social services, education and health care systems have resulted in loss of cultural knowledge and language in Indigenous communities and poorer outcomes in many of the social determinants of health compared with the non-Indigenous population, and significant 
trauma for Indigenous peoples with lasting inter-generational effects (Cornell 2006; King et al. 2009). The impact of these previous traumatic events on family structures and high level of substance use reported among Indigenous adults has left its mark on Indigenous adolescents, who, consequently, experience higher levels of psychological distress as well as an increased susceptibility to substance use and related harms, compared to their non-Indigenous counterparts. For example, binge drinking (consuming 5 or more drinks in one session) rates among Indigenous adolescents in the USA were up to five times higher than all other ethnicities (Centers for Disease Control and Prevention 2018). While rates of tobacco smoking are reducing, Indigenous adolescents, in the USA are nine times more likely to smoke (Centers for Disease Control and Prevention 2018), those in New Zealand three times more likely (Ministry of Health 2015) and those in Canada twice as likely (Reading and Wien 2009) compared to non-Indigenous adolescents. Indigenous adolescents are also more likely to report cannabis use: five times higher in Canada and in the USA (Beauvais 1992). Injecting drug rates

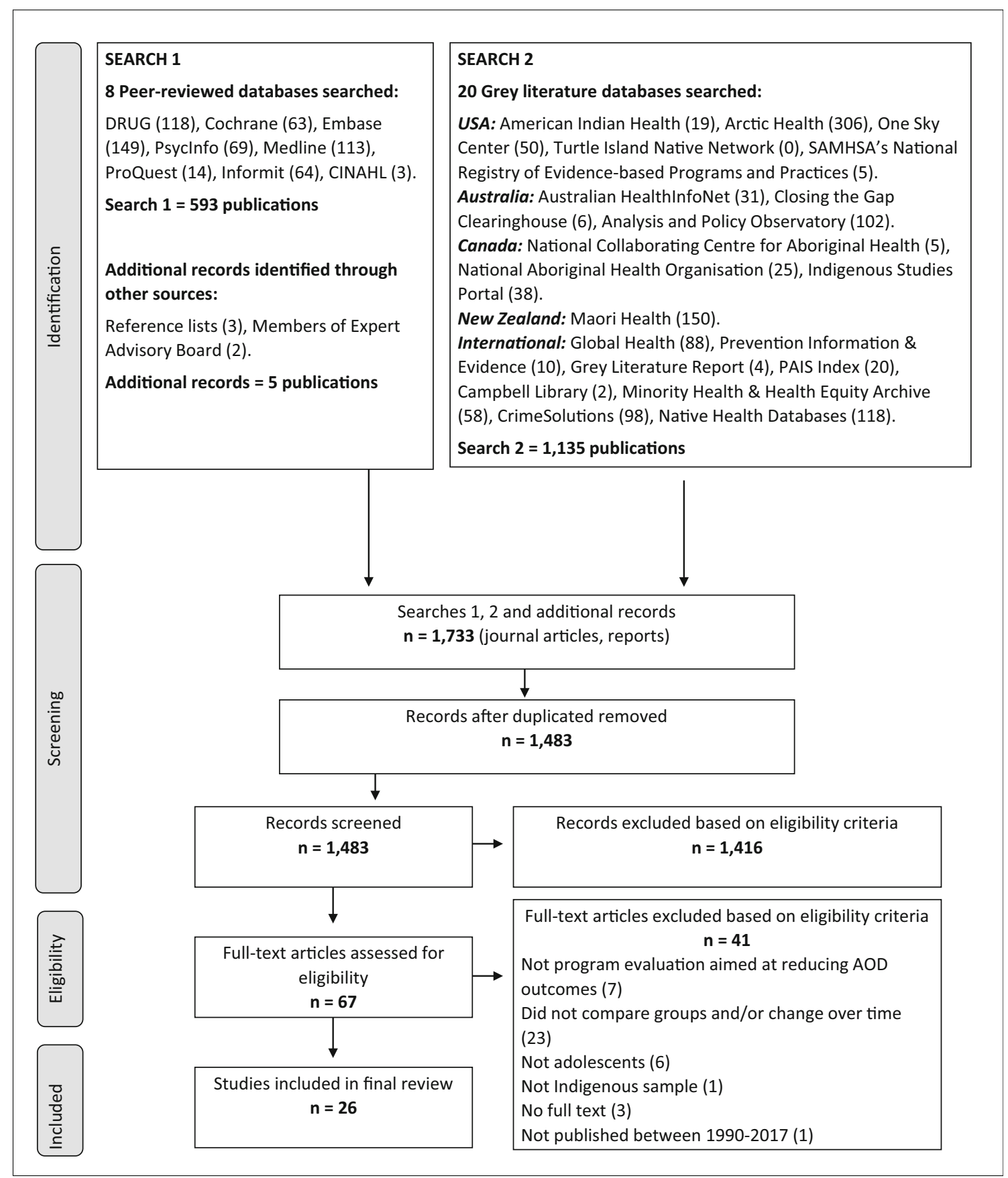

Fig. 1 PRISMA flow diagram: systematic search strategy to identify studies evaluating substance use prevention programs for Indigenous youth 
Table 1 Outcomes measured in included studies

\begin{tabular}{lllr}
\hline & Iatrogenic & Null & Beneficial \\
\hline Substance use frequency $(n=19)$ & $1(6 \%)$ & $8(38 \%)$ & $10(56 \%)$ \\
Substance-related knowledge $(n=10)$ & 0 & $4(20 \%)$ & $7(60 \%)$ \\
Attitudes towards substances $(n=5)$ & 0 & $2(33 \%)$ & $3(67 \%)$ \\
Substance resistance strategies $(n=2)$ & 0 & $1(50 \%)$ & $1(50 \%)$ \\
Intention to use $(n=2)$ & 0 & 0 & $2(100 \%)$ \\
Substance use initiation $(n=2)$ & 0 & $1(50 \%)$ & $1(50 \%)$ \\
\hline
\end{tabular}

are three times higher among Indigenous adolescents compared to non-Indigenous adolescents in Australia (Bryant et al. 2016) and the USA (Centers for Disease Control and Prevention 2018). Furthermore, Indigenous adolescents are likely to commence drug use 2 to 6 years younger compared to their non-Indigenous counterparts (Australian Institute of Health and Welfare 2006). Early onset, and escalation, of substance use among Indigenous adolescents have been identified as risk factors for substance-related disorders and associated problems such as poorer educational outcomes and comorbid mental health problems, later in life (Behrendt et al. 2009; Degenhardt et al. 2016; Kunitz 2008; Whitesell et al. 2009; Windle et al. 2008). Prevention of adolescent substance use has therefore been identified as a key strategy to improve Indigenous wellbeing (Australian Government 2013; Dickerson et al. 2018; King et al. 2009).

Substance use prevention strategies have shown to be effective for non-Indigenous adolescents, including school-based, community-based and family-based programs (Foxcroft and Tsertsvadze 2012; Newton et al. 2017). Given the unique historical and cultural contexts, non-Indigenous programs likely require a cross cultural translation for Indigenous adolescents, mapped against different communication styles and language, accounting for situational and place context, and different perspectives of health and identity (Castro and Yasui 2017; Dickerson et al. 2018). Programs adapted from existing non-

Table 2 Components of prevention programs leading to beneficial substance-related outcomes amongst Indigenous youth

\begin{tabular}{|c|c|c|c|c|c|c|}
\hline & $\begin{array}{l}\text { Substance } \\
\text { use } \\
\text { frequency } \\
(n=10) \\
N(\%)\end{array}$ & $\begin{array}{l}\text { Substance- } \\
\text { related } \\
\text { knowledge } \\
(n=7) \\
N(\%)\end{array}$ & $\begin{array}{l}\text { Attitudes } \\
\text { towards } \\
\text { substances } \\
(n=3) \\
N(\%)\end{array}$ & $\begin{array}{l}\text { Substance } \\
\text { resistance } \\
\text { strategies } \\
(n=1) \\
N(\%)\end{array}$ & 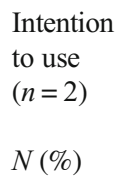 & $\begin{array}{l}\text { Substance } \\
\text { use } \\
\text { initiation } \\
(n=1) \\
N(\%)\end{array}$ \\
\hline $\begin{array}{l}\text { Community resource development } \\
\text { Elders, parents, students, community leaders and members }\end{array}$ & $5(50 \%)$ & $5(71 \%)$ & $3(100 \%)$ & $1(100 \%)$ & $2(100 \%)$ & $1(100 \%)$ \\
\hline $\begin{array}{l}\text { Cultural knowledge enhancement } \\
\text { Traditional values, concepts, ceremony, storytelling, } \\
\text { ancestry, prayer }\end{array}$ & $9(90 \%)$ & $4(57 \%)$ & $2(66 \%)$ & $1(100 \%)$ & $2(100 \%)$ & $1(100 \%)$ \\
\hline $\begin{array}{l}\text { Skill development } \\
\text { Goal setting, problem-solving, decision-making, peer } \\
\text { support, communication, assertiveness, resilience, } \\
\text { interpersonal, occupational, AOD resistance skills }\end{array}$ & $10(100 \%)$ & $4(57 \%)$ & $2(66 \%)$ & $1(100 \%)$ & - & $1(100 \%)$ \\
\hline $\begin{array}{l}\text { Indigenous facilitators } \\
\text { Local Indigenous community members received training }\end{array}$ & $4(40 \%)$ & $3(42 \%)$ & $1(33 \%)$ & $1(100 \%)$ & - & $1(100 \%)$ \\
\hline $\begin{array}{l}\text { Substance use education } \\
\text { Effects of use, addiction }\end{array}$ & $6(60 \%)$ & $4(57 \%)$ & $2(66 \%)$ & - & $1(50 \%)$ & - \\
\hline $\begin{array}{l}\text { Trained worker/teacher facilitation } \\
\text { Social workers, teachers or youth workers received } \\
\text { training in specific program }\end{array}$ & $5(50 \%)$ & $3(42 \%)$ & - & - & $1(50 \%)$ & - \\
\hline $\begin{array}{l}\text { Health education } \\
\text { Holistic concepts of health, physical activity, nutrition }\end{array}$ & $3(30 \%)$ & $2(29 \%)$ & - & - & - & $1(100 \%)$ \\
\hline $\begin{array}{l}\text { Mental health education } \\
\text { Self-talk, depression, suicide, identifying personal } \\
\text { strengths, stress management }\end{array}$ & $2(20 \%)$ & - & - & - & - & - \\
\hline $\begin{array}{l}\text { Relationships } \\
\text { Importance of community, family, role models, family } \\
\text { conflict management }\end{array}$ & $2(20 \%)$ & - & - & - & - & - \\
\hline $\begin{array}{l}\text { Recreational } \\
\text { Sport, festivals, painting, discos, film-making }\end{array}$ & $2(20 \%)$ & $2(29 \%)$ & - & - & - & - \\
\hline $\begin{array}{l}\text { Booster session } \\
\text { Repeating key messages } 3 \text { to } 6 \text { months later }\end{array}$ & $2(20 \%)$ & - & $1(33 \%)$ & - & - & - \\
\hline $\begin{array}{l}\text { Computerised delivery } \\
\text { Online-based program }\end{array}$ & - & - & $1(33 \%)$ & - & $1(50 \%)$ & - \\
\hline
\end{tabular}


Indigenous programs (culturally adapted programs) or developed specifically for the local Indigenous cultural context (culture-based programs) are likely to be effective in the prevention of alcohol and other drug use (Belone et al. 2017; Dickerson et al. 2018; Leske et al. 2016).

To date, a comprehensive synthesis of the international evidence for Indigenous substance use prevention programs has not been conducted. This systematic review will address this gap by reviewing the effectiveness of substance use prevention programs for Indigenous adolescents in the USA, Canada, Australia and New Zealand. More specifically, for Indigenous adolescents, this review will investigate (a) the outcomes, type (culturally adapted, culture-based, unadapted), setting (community, school, family) and context (multi-cultural, Indigenous-specific) of prevention programs; (b) the common components of beneficial substance use prevention programs; and (c) the methodological quality of evaluations of substance use prevention programs.

\section{Methods}

\section{Search Strategy}

This systematic review followed the Preferred Reporting Items for Systematic Review and Meta-Analysis (PRISMA) guidelines (Moher et al. 2009) and a pre-specified, published protocol (Snijder et al. 2018; PROSPERO registration number: CRD42017081885). Figure 1 summarises the complete study selection process. A detailed description of the methods can be found in Snijder et al. (2018). Twenty-eight electronic databases were searched using search terms developed to identify evaluations of substance use prevention programs for Indigenous adolescents in the USA, Canada, Australia and New Zealand (Appendix Table 3). Reference lists were manually searched, and publications were received from researchers in the field.

Studies were included if they (a) evaluated a prevention program aiming to reduce substance use and related outcomes, (b) compared an experimental group to a control group and/or assessed changes over time, (c) included participants aged 10 to 19 years, (d) comprised at least $50 \%$ of participants who identified as Indigenous and/or there was a specific subanalysis for Indigenous participants, (e) were published between 1 January 1990 and 31 August 2017, and (f) full text was available to the authors.

BL screened all titles and abstracts based on the eligibility criteria, and a random selection of $25 \%$ of studies was independently screened by MS to ensure accuracy in the study selection. There was an agreement on $90 \%$ of studies, and consultation was held between the two authors to reconcile the disagreements. MS and BL independently assessed the eligibility of 67 full-text articles, with high inter-rater agreement between the two authors for this assessment $(96 \%$; $\mathrm{k}=$
0.829). Again, consultation was held between the two authors to reconcile differences of opinion.

\section{Data Extraction and Analysis}

Data relating to the program and the evaluation of the program were extracted from the included studies. Program types were culture-based, culturally adapted or unadapted (Leske et al. 2016). Program setting comprised school, community, family-based programs or multi-setting programs (Lee et al. 2013). Program context was defined as being conducted an Indigenous-specific environment (e.g. reservation) or a multicultural environment (e.g. public-school classroom).

Data relating to the evaluation of the program included the sample size and composition, the study design and substancerelated and non-substance-related outcomes. Substancerelated outcomes were substance use frequency, substancerelated knowledge, attitudes towards substances, substance resistance strategies, intention to use and substance use initiation (Lee et al. 2013). Due to the heterogeneity of study designs and outcomes, a narrative synthesis of the results is provided, rather than a meta-analysis.

Programs were identified as beneficial if there were beneficial effects on more than $50 \%$ of substance-related outcomes measured in the study. "Beneficial effects" are defined as any positive changes reported in the study (e.g. statistically significant improvements, percentage changes, qualitatively recorded improvements). Common program components were determined by identifying the components of these programs that showed broader beneficial impacts.

\section{Critical Appraisal of Evaluation Methodology}

The methodological quality of quantitative studies was assessed using the Quality Assessment Tool for Quantitative Studies from the Effective Public Health Practice Project (EPHPP) (Thomas et al. 2004), and the methodological quality of qualitative study components was assessed using a modified version of the qualitative tool by Long and Godfrey (2004). Assessment of both quantitative and qualitative studies was conducted by BL. A random selection of $25 \%$ of studies was independently appraised by MS; there was $100 \%$ agreement.

\section{Results}

Of the 1483 articles screened, 26 publications reporting results of evaluations of substance use prevention programs for Indigenous youth were eligible. Reasons for exclusion are detailed in Fig. 1. Of the 26 publications, 24 studies evaluating 27 prevention programs were identified from peer-reviewed databases and two studies were identified from the grey 
literature. Eighteen (70\%) studies were conducted in the USA, six $(23 \%)$ in Australia and two $(8 \%)$ in Canada, while no studies in New Zealand met the eligibility criteria. Thirteen programs targeted multiple substances: alcohol was the most commonly targeted substance $(n=15)$, followed by tobacco $(n=12)$ and cannabis $(n=10)$. Other substances included stimulants $(n=1)$, inhalants $(n=2)$ and analgesics $(n=1)$. Appendix Table 3 provides an overview of all included studies, the evaluated programs and the evaluation outcomes.

\section{Outcomes, Type, Setting and Context of Prevention Programs for Indigenous Adolescents}

Outcomes of the evaluations are listed by substance-related outcome type in Table 1. Frequency of use was measured in $73 \%$ of studies, $39 \%$ measured substance-related knowledge, $19 \%$ measured attitudes towards substances, and $8 \%$ measured substance resistance strategies, intention to use and substance use initiation. Beneficial outcomes were found for 50 to $100 \%$ of studies across all outcome types. In total, 14 programs were found to be beneficial with positive effects on more than $50 \%$ of measured substance-related outcomes.

In terms of program type, fifteen (58\%) studies evaluated a culture-based program, ten $(38 \%)$ studies evaluated a culturally adapted program and one (4\%) study evaluated an unadapted program. Cultural adaptation of non-Indigenous programs included translation of concepts into local Indigenous language and concepts, developing cultural images and the adaptation of activities to include cultural activities such as prayer, dancing and circle conversations. Three studies evaluated the Keepin' it REAL program: two were a cultural adaptation of this program called Living in 2 worlds (Kulis et al. 2013; Kulis et al. 2016), and one was unadapted (Dixon et al. 2007). Dixon et al. (2007) found iatrogenic outcomes for Indigenous adolescents, namely an increase in cannabis use following the program. The pilot of the adapted program produced beneficial outcomes for substance resistance strategies (Kulis et al. 2013). The efficacy trial showed improvements in substance-related knowledge, but no statistically significant improvements in substance resistance strategies or substance use frequency (Kulis et al. 2016).

In terms of program setting, thirteen $(50 \%)$ evaluated programs were school-based, five (19\%) were community-based, five (19\%) combined school and family, one (4\%) combined community and school, two (8\%) combined family and community-based programs, and four (15\%) were delivered in community, family and school settings. Family involvement in programs was primarily through one-off workshops or pamphlets given to parents and was not specifically evaluated in any study. Two studies evaluated programs that were delivered in a single setting compared to multiple settings: Schinke et al. (2000) compared a school-based program to the same program combined with a community-based program and Komro et al. (2017) compared a school-based program (CONNECT), a community-based program (CMCA) and a program where $C O N N E C T$ and $C M C A$ were combined. These studies found the multi-setting programs had a smaller effect on substance use than the school- or community-based program on their own (Komro et al. 2017), or that there was no added benefit of a community component to the school-based program (Schinke et al. 2000).

In terms of the context in which prevention programs were implemented, $12(46 \%)$ were implemented in reservation/ discrete Indigenous communities where all community members identify as Indigenous, ten (38\%) were implemented in an urban setting, two in Indian territory and two in rural communities. Programs implemented in non-Indigenous specific areas still had $100 \%$ Indigenous participants in the evaluation study, except for five studies which had between 16 and $90 \%$ Indigenous participants and were all school-based (Carter et al. 2007; Dixon et al. 2007; Komro et al. 2017; Malseed et al. 2014; Petoskey et al. 1998).

\section{Common Components in Effective Substance Use Prevention Programs for Indigenous Youth}

Table 2 lists which components of prevention programs had beneficial effects on which substance-related outcome for Indigenous youth. Nine (64\%) beneficial programs were developed by, or together with, the community. Community involvement included parents, youth, community leaders, parents and other community members providing input in program development and feedback on versions of the program. Nine (64\%) beneficial programs incorporated cultural knowledge enhancement, including integration of cultural activities (e.g. ceremonies, storytelling, rituals, dancing), learning about traditional beliefs and practices, integration of culturally specific concepts and use of culturally appropriate artwork and designs. Eleven (79\%) beneficial programs had a skill development component, which included problem-solving, substance resistance strategies, interpersonal skills, decisionmaking and self-management skills. Substance use education components were included in eight $(57 \%)$ beneficial programs and included information on the effects of substances, shortand long-term consequences and information about addiction.

In addition to these four most commonly used components, other components included the use of facilitators trained in program delivery (6 programs) and Indigenous program facilitators (5 programs). Four programs used health education strategies, which included providing healthy alternatives to substance use, incorporating a holistic concept of wellbeing and media campaigns about healthy lifestyles. Three programs included a booster session 3 to 6 months following program implementation and three programs included recreational activities, such as sports, festivals, painting, going out bush and filmmaking. 
Two programs were delivered online: SmokingZine and Boy and Woman Bear. SmokingZine was an adaptation of a non-Indigenous Web site and included educational modules with culturally relevant content and imagery. It was found to reduce intention to use tobacco, reduce positive beliefs about tobacco smoking, and increase likelihood to help others quit smoking (Bowen et al. 2012). Boy and Woman Bear was an illustrated story presented on a computer; the evaluation found no improvements in tobacco knowledge (Schinke et al. 1994).

\section{Methodological Quality of Substance Use Prevention Program Evaluations Among Indigenous Youth}

All 26 included studies used quantitative evaluation methods and four studies also included a qualitative component (Baydala et al. 2014; Donovan et al. 2015; Gray et al. 1998; Lee et al. 2008).

\section{Quantitative Study Components}

Appendix Table 4 shows the outcome of the methodological quality assessment of quantitative studies. Five (19\%) studies had a strong quality rating according to the quality assessment tool from EPHPP, seven $(27 \%)$ had a moderate rating and fourteen $(54 \%)$ studies had a weak rating. Participants were deemed likely to be representative of the population in three (12\%) studies. Five (19\%) studies were RCTs, three (12\%) studies were controlled clinical trials, five (19\%) studies were cohort clinical trials and thirteen $(50 \%)$ studies were cohort studies. Confounding factors were discussed in all studies; 16 studies did not find significant confounding factors and seven (27\%) studies controlled for significant confounding variables. Thirteen $(50 \%)$ studies used validated outcome measurement tools and thirteen $(50 \%)$ studies used reliable measurement tools. Withdrawals and drop-outs were reported in fourteen $(54 \%)$ studies. Program completion rates were recorded in fourteen $(54 \%)$ studies. Program fidelity was measured in nine (35\%) studies (Table 5).

\section{Qualitative Study Components}

All four studies with a qualitative component provided some description of the data collection and analysis methods. Detailed data collection and analysis descriptions (e.g. participant recruitment, focus group procedures and a clear description of the data that was recorded) were provided in two of the four $(50 \%)$ studies (Baydala et al. 2014; Lee et al. 2008). The potential for researcher bias was discussed in one (25\%) study (Donovan et al. 2015) and three of the four (75\%) studies described the implications of their findings (Baydala et al. 2014; Donovan et al. 2015; Lee et al. 2008).

\section{Discussion}

This study systematically reviewed the literature on substance use prevention programs for Indigenous youth in the USA, Canada, Australia and New Zealand. The review identified 26 eligible studies, and results indicated that substance use prevention programs for Indigenous youth can reduce substance use frequency and intention to use, improve substance-related knowledge, attitudes and resistance strategies, and delay substance use initiation. In terms of program type, only one included study delivered an unadapted program directly to Indigenous adolescents, whereas all other programs were either cultural adaptations of mainstream programs, or cultural-based programs. Most studies were delivered in a school setting, either as the sole setting, or combined with family or community elements. All but five studies were delivered to a completely Indigenous participant group.

The most commonly included components in beneficial prevention programs were the inclusion of substance use education, cultural knowledge enhancement, skill development and the involvement of the community in the development of the program. The findings of this literature review should be interpreted in the light of the methodological quality of the studies, which was weak for $54 \%$ of the included studies, moderate for $27 \%$ and strong for $19 \%$ included studies. This review therefore emphasises the need for better quality evaluation studies to build a stronger evidence base around effective substance use and related harms prevention for Indigenous adolescents.

\section{Outcomes, Type, Setting and Context of Prevention for Indigenous Youth}

Only $8 \%$ of included studies measured - intention to, and initiation of, substance use, which are important measures of successful prevention considering that every year of delaying substance use reduces the likelihood of a substance use disorder by $9 \%$ (Grant et al. 2001; Newton et al. 2014). Given the younger age of substance use initiation amongst Indigenous adolescents (Australian Institute of Health and Welfare 2006), delay of initiation should be targeted by future substance prevention programs and measured in evaluation studies.

It is promising to see that all, except one program were either culturally adapted or cultural-based programs. Cross-cultural translation of prevention concepts is important for programs to be appropriate and effective for the target group (Castro and Yasui 2017; Dickerson et al. 2018). The most common setting for programs was schools, which have the potential to reach many young people and has been identified as a priority setting for prevention (Barry et al. 2013). This setting adds complexity due to the multicultural nature of classrooms in the USA, Canada and Australia. In the USA, for example, only 
$13 \%$ of approximately 378,000 Native American adolescents go to an American Indian school (Bureau of Indian Education 2017), leaving most Native American students attending schools with students of other cultural backgrounds (Hecht et al. 2003). While another study identified that multicultural substance use prevention was equally effective as cultural-based prevention for students with Hispanic, European and African-American backgrounds (Hecht et al. 2003), the findings of this review suggest this may not be the case for Indigenous students. Dixon et al. (2007) argued that reservation/mission living, and a history of colonisation and dispossession have created a unique cultural context for Indigenous students that requires an appropriately tailored prevention approach. Given that most Indigenous students in the USA, Canada, Australia and New Zealand attend schools with students from a range of cultural backgrounds, the challenge for future school-based substance use prevention research is to develop programs that are culturally inclusive and effective for Indigenous students as well as students from other cultural backgrounds.

Despite the importance of family and community in Indigenous cultures (Kirmayer et al. 2003) and as a protective factor against substance use and related harms (Johnston and Thomas 2008), only one third of prevention programs identified in this review were community- or family-based. The included "family-based" programs only engaged the families through one-off workshops or pamphlets and none of the included studies evaluated the impact of the family component specifically. While familybased programs have recently been developed for Indigenous adolescents, such as the Strengthening Families Program (Kumpfer et al. 2010) and the Family Listening/Circle Program (Belone et al. 2017), none of these had published evaluations at the time of this literature review. The important role of family and community in Indigenous cultures and the evidence for the effectiveness of family- and community-based programs in nonIndigenous populations (Calabria et al. 2012; Templeton et al. 2010), highlights an area for further improvements to prevent substance use among Indigenous adolescents.

\section{Common Components of Effective Substance Use Prevention}

The fourteen programs with beneficial substance-related outcomes for Indigenous adolescents used a combination of skill development, cultural knowledge enhancement and/or substance education. These key elements are in line with effective principles of substance use prevention for non-Indigenous populations, and it is promising that this is reflected for Indigenous adolescents (Lee et al. 2016; Newton et al. 2014). The finding that cultural knowledge enhancement was common in all effective programs highlights the importance of cultural adaptation and sensitivity to local cultural characteristics (Newton et al. 2014).

The majority of the 14 beneficial programs were developed with the local Indigenous community, a finding which aligns with international guidelines (United Nations 2008) and previous research demonstrating the importance of Indigenous ownership for effective program development (Lee et al. 2013; Snijder et al. 2015). It has now been generally accepted that Indigenous people need to be involved in every stage of the planning, implementation and evaluation of drug prevention programs (Dickerson et al. 2018).

While this review set out to assess the effectiveness of computerised and online prevention programs compared to traditional programs (Snijder et al. 2018), only two computerised programs were identified (Bowen et al. 2012; Schinke et al. 1994). This lack of use of technology in delivering substance use prevention for Indigenous adolescents is in line with findings from previous reviews and highlights an area for future development (Doran et al. 2017; Lee et al. 2013). Benefits of computerised interventions have been documented elsewhere and are thought to be especially applicable to disadvantaged populations as their flexibility can overcome issues relating to intervention implementation in hard-to-reach and culturally diverse populations (Chou et al. 2013). Given the potential for computerised programs to address issues with delivery, the high rates of technology and internet use amongst Indigenous adolescents (Garakani 2014; McNair Ingenuity Research 2014; Rice et al. 2016) and effectiveness of computer- and Internet-delivered substance use prevention in non-Indigenous populations (Champion et al. 2016), future research should explore the effectiveness of the use of computers and online technology in the delivery of substance use prevention with Indigenous adolescents.

\section{Methodological Considerations}

This review identified five RCTs and three CCTs; however, only two of the RCTs were methodologically strong according to the critical appraisal using the EPHPP tool. This poor methodological quality likely reflects the challenges related to Indigenous-specific research as well as a lack of financial commitment in this field. Better quality research and reporting is required to improve the evidence around substance use prevention for Indigenous adolescents. Others have argued that the use of traditionally preferred research designs, such as RCTs, may be less appropriate for use with Indigenous populations (Clifford et al. 2011; Dickerson et al. 2018). Quality of evaluation research in this field can be improved by increasing the use of practical and alternative research 
designs, such as cluster RCTs and multiple baseline designs (Clifford and Shakeshaft 2017; Dickerson et al. 2018). Researchers and funding organisations should strive to prioritise rigorously conducted evaluation research in this field and be open to alternative designs.

Further compromising the findings of studies in this review is the lack of validated and reliable measurement tools used in evaluations, with only half of the studies using such measures. This is less than optimal considering that using measures that have not been specifically developed for use with Indigenous populations will likely under estimate the real levels of substance use (Chikritzhs and Brady 2006). The low level of use of reliable and valid measures reflects the lack of available measures developed specifically for Indigenous populations; a 2017 bibliometric review only identified 19 studies developing and/or validating drug and alcohol measurement for Indigenous populations across the USA, Australia, Canada and New Zealand between 1993 and 2014 (Clifford and Shakeshaft 2017). More research funding and efforts should be allocated to developing reliable and valid substance outcome measures for use with Indigenous populations. Such research should be developed with input from Indigenous communities about how impact can be measured, and cultural elements can be incorporated (Belone et al. 2012; Lee et al. 2018; Mushquash and Bova 2007).

\section{Limitations}

A potential limitation of this systematic review is the Western interpretation of what constitutes beneficial outcomes. It is important to acknowledge that Western models used in this and other reviews are not the only way of knowing and that Indigenous populations in the USA (Dickerson et al. 2018), Australia (Cochran et al. 2008), New Zealand (Smith 2012) and Canada (Schnarch 2004) have their own ways of gathering and sharing knowledge that should be acknowledged and integrated into research. A barrier to integrating Indigenous ways of knowing in the current literature review was the embedded Western models in the studies included in this review. This review recommends the integration of Indigenous ways of knowing and Western research models in future substance use prevention research with Indigenous populations to ensure that the outcomes are in line with the cultural context and reflect what the local communities identify as important outcomes.

Another potential limitation is the restriction to four countries, even though, globally, there are 70 countries with Indigenous populations (United Nations 2006). It is possible that effective substance use prevention programs for Indigenous adolescents in other countries were overlooked that could be beneficial for Indigenous adolescents in the USA, Canada, Australia and New Zealand. Despite this possibility, the generalisability to the countries included in this review cannot be assumed, given the differences in their cultural and colonisation history. The review was deliberately limited to these four countries as they have a comparable history of being colonised by English settlers and are a minority in an English-dominant culture, with comparable consequences in terms of health and wellbeing outcomes (Cornell 2006). This comparability of Indigenous peoples in the USA, Canada, Australia and New Zealand makes the findings of included studies more generalisable to these four countries.

A methodological limitation of this review is the classification of studies as beneficial based on the percentage of beneficial outcomes reported in the study. This may have penalised studies for measuring more outcomes. In this review, there was a slight difference in the number of outcomes measured in studies marked as null compared to beneficial studies. On average, studies with null effects (50\% or less beneficial outcomes) measured four outcomes, whereas beneficial studies (more than $50 \%$ of beneficial outcomes) measured three outcomes. While this is not ideal, it was a useful method of narratively summarising outcomes of the included studies. However, as a consequence of this approach, conclusions about effectiveness of drug prevention for Indigenous youth could not be made. Finally, this review included some studies with a small sample size and these findings should be interpreted with caution as they may lack statistical power to show a statistically significant or clinically meaningful result.

\section{Conclusion}

Overall, the results of this review indicate that substance use prevention programs have the potential to produce beneficial substance-related outcomes for Indigenous adolescents, especially when they are developed with Indigenous people and include components of skill development, cultural knowledge enhancement and substance-related education. However, methodological quality of the included evaluations lacked the rigour required to draw conclusive statements about the effectiveness of substance use prevention programs for Indigenous adolescents. There is an urgent need for more financial and time investment in conducting rigorous evaluations using practical and alternative research designs, such as multiple baseline designs and cluster RCTs, to create a strong evidence base of what works to prevent substance use among Indigenous youth. 


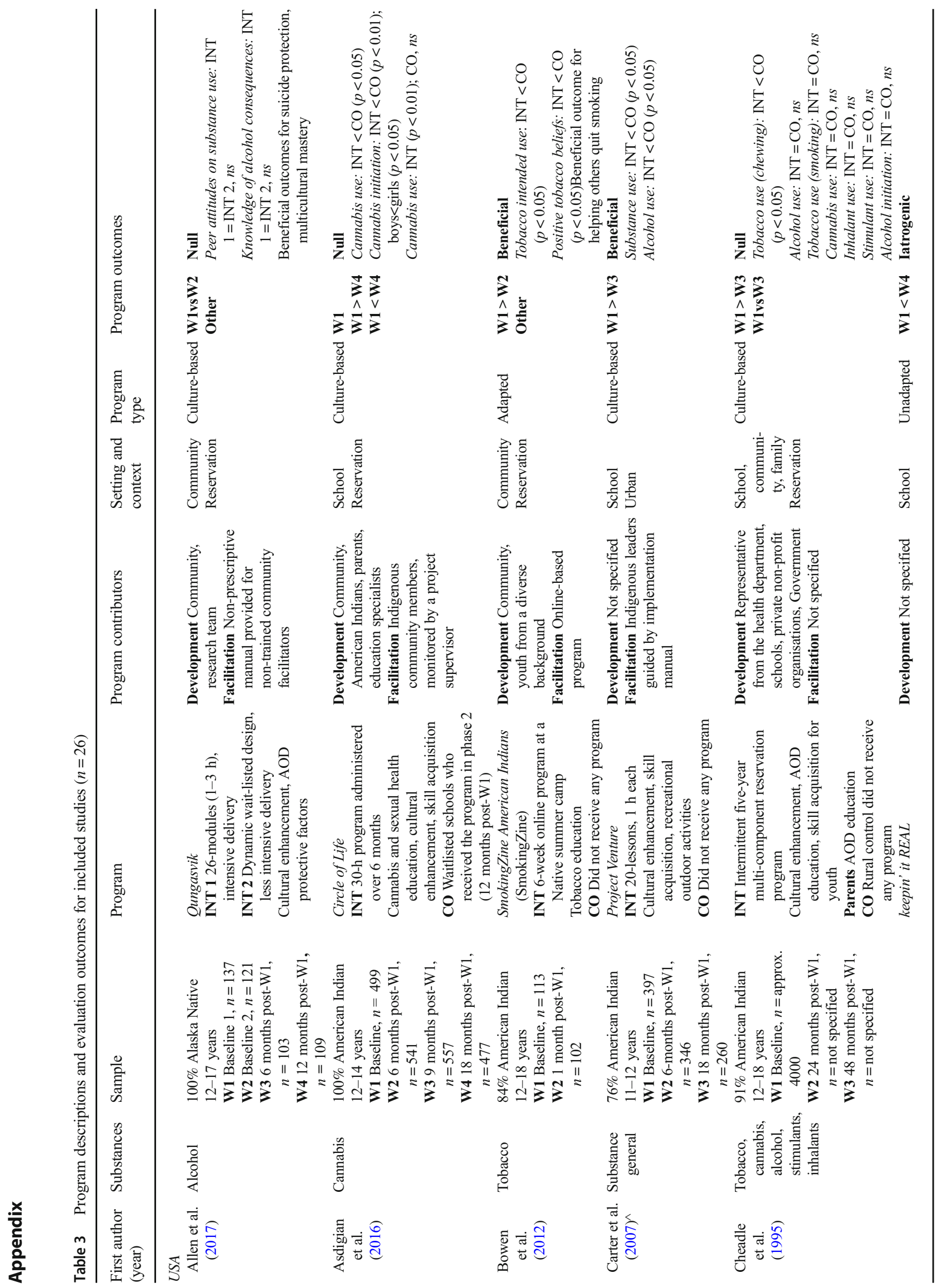




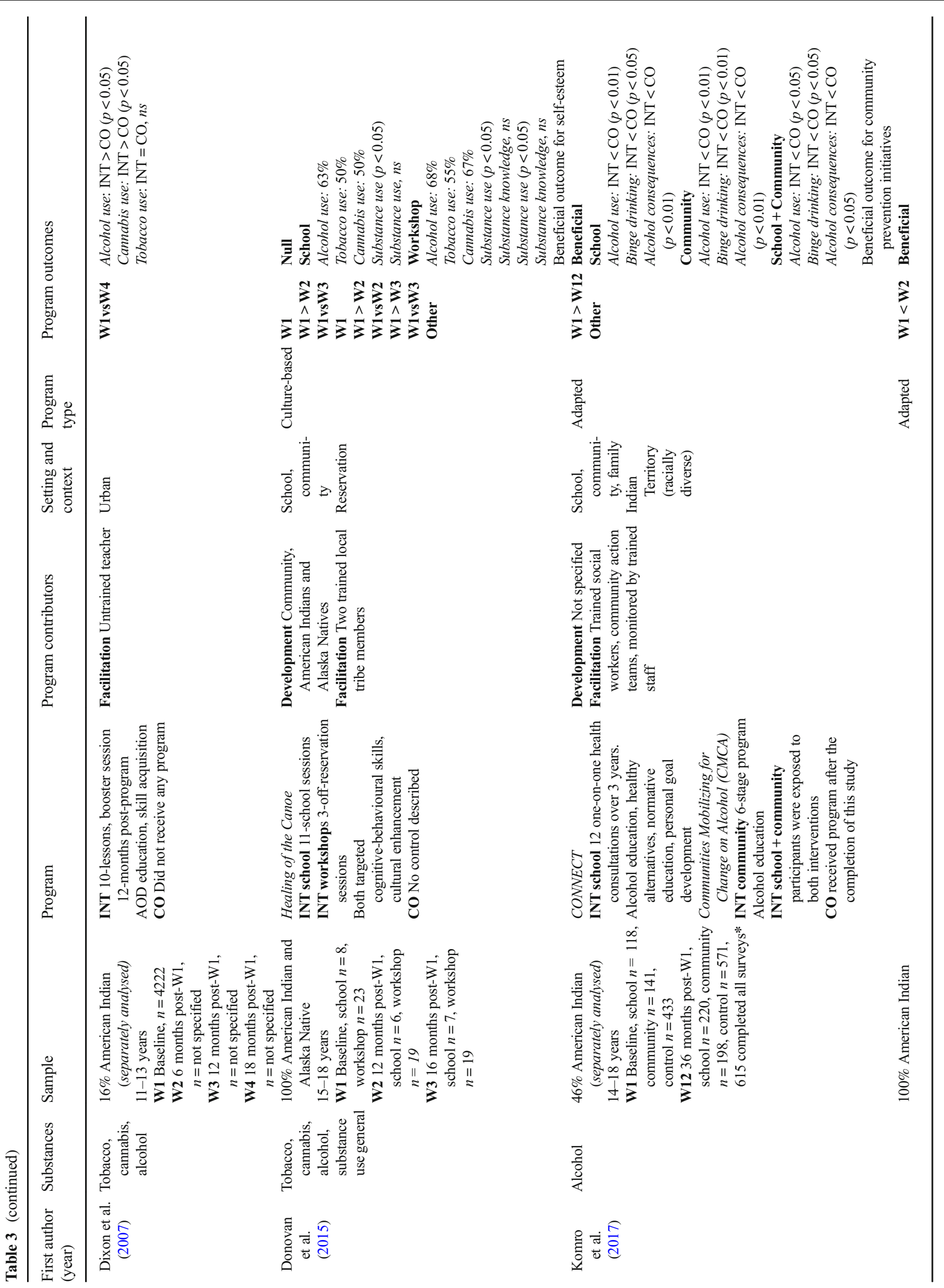




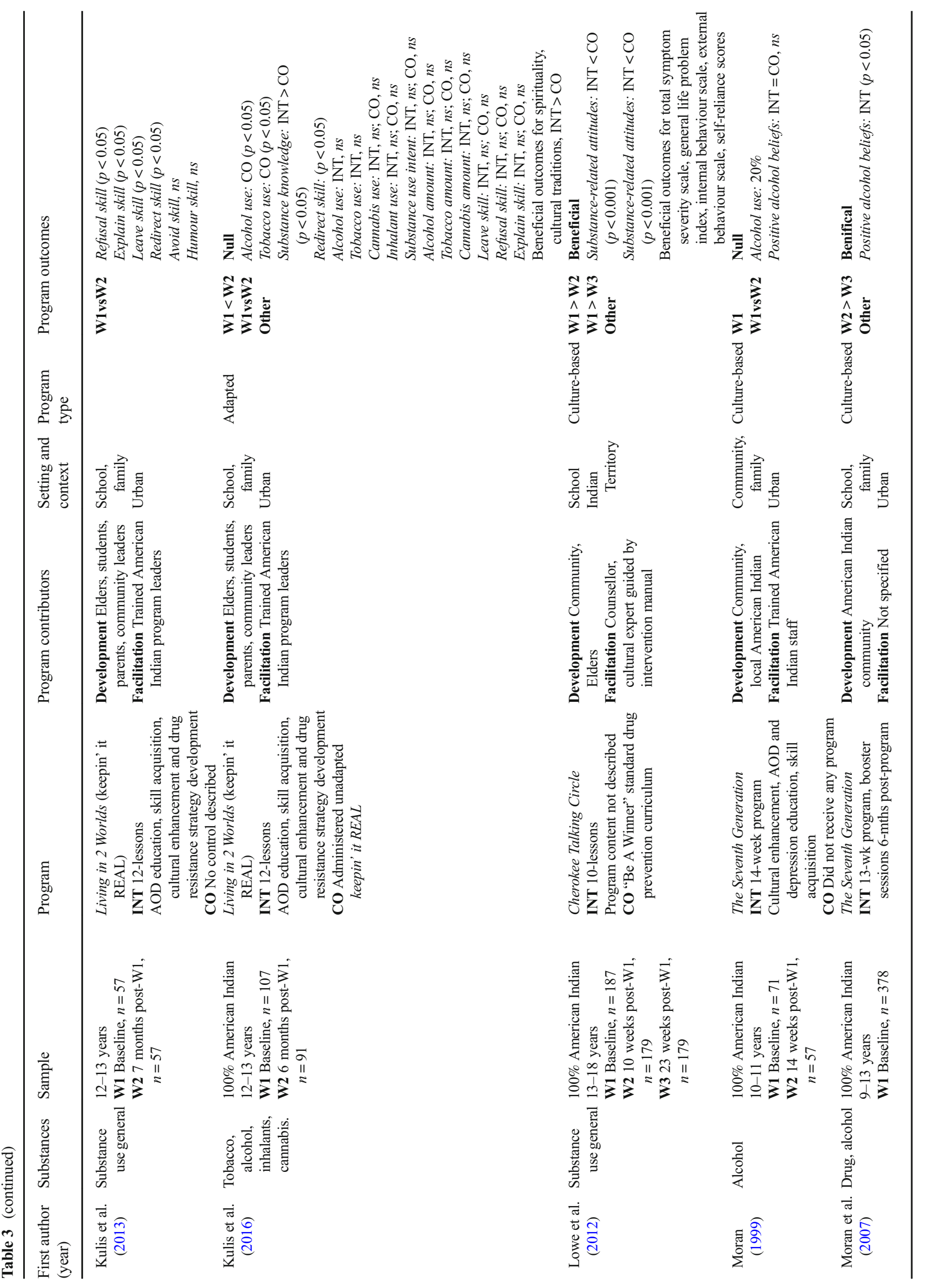




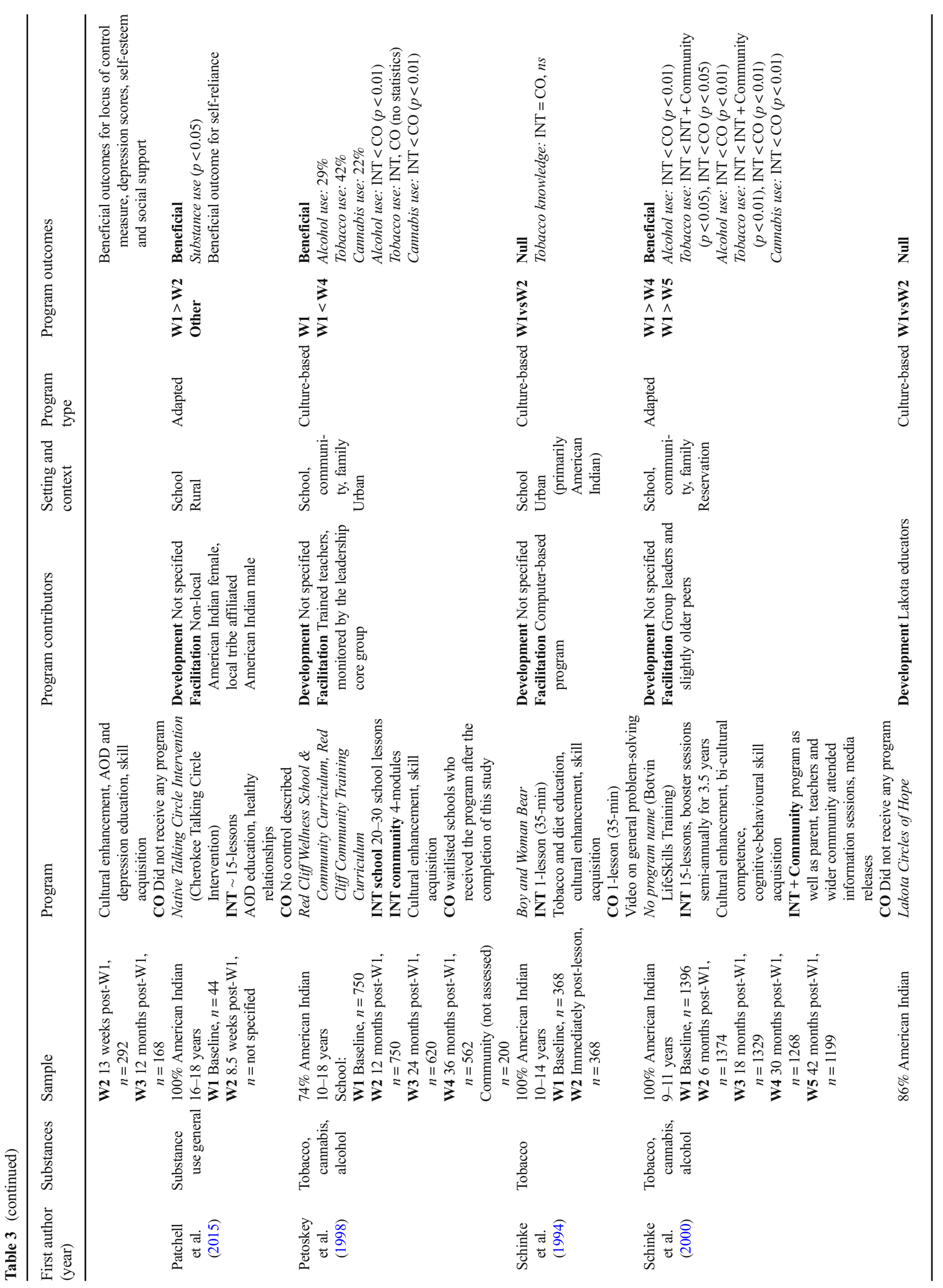




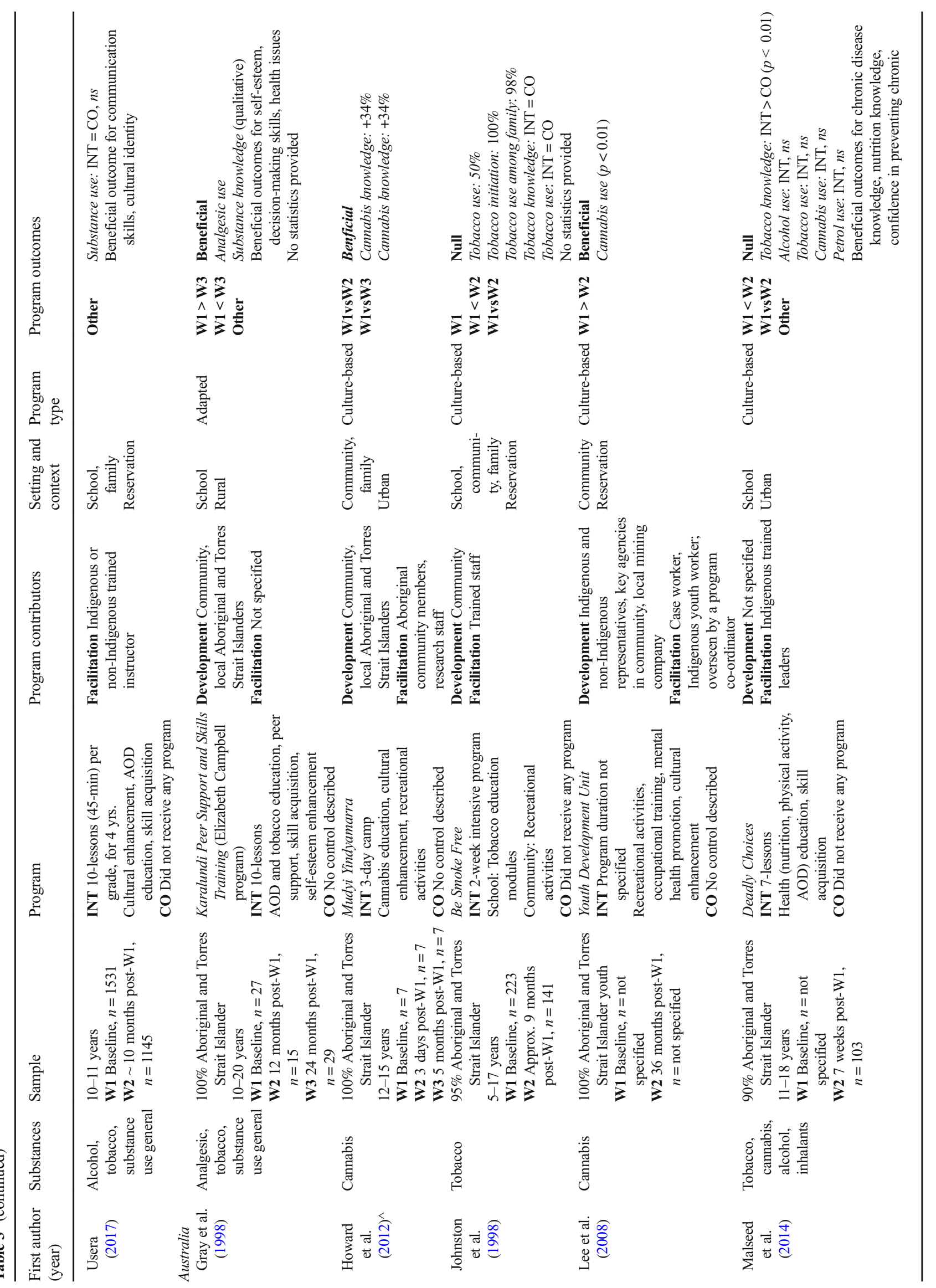




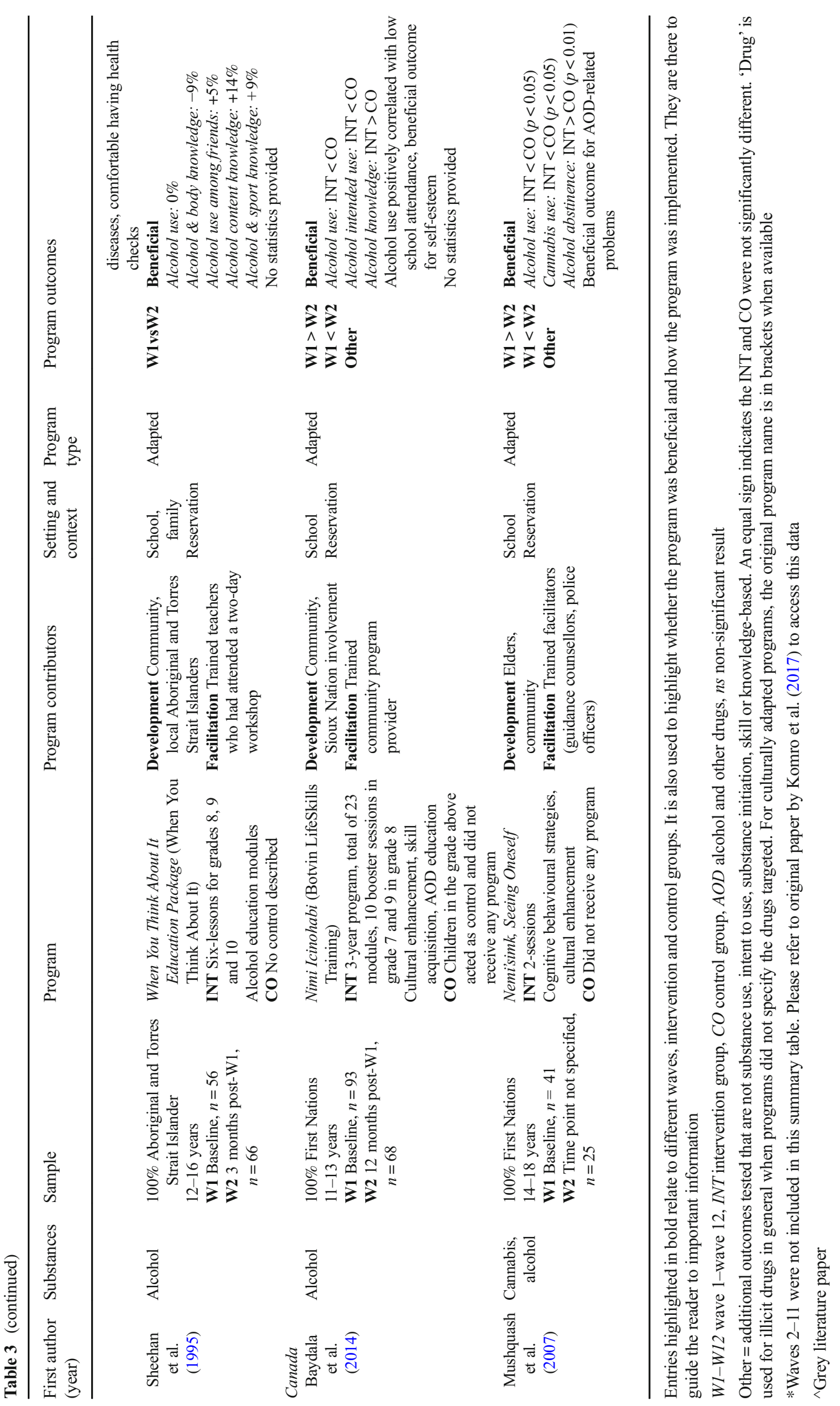


Table 4 Critical appraisal of quantitative components of included studies $(n=26)$

\begin{tabular}{llllllll}
\hline $\begin{array}{l}\text { First author } \\
\text { (year) }\end{array}$ & $\begin{array}{l}\text { Selection } \\
\text { bias }\end{array}$ & $\begin{array}{l}\text { Study } \\
\text { design }\end{array}$ & Confounds & $\begin{array}{l}\text { Data } \\
\text { collection } \\
\text { methods }\end{array}$ & $\begin{array}{l}\text { Withdrawal } \\
\text { and drop- } \\
\text { outs }\end{array}$ & Intervention integrity & Analysis \\
\hline
\end{tabular}

USA

Allen et al. Moderate Moderate Strong Strong Strong (2017)

$\begin{array}{llllll}\begin{array}{c}\text { Asdigian } \\ \text { et al. } \\ (2016)\end{array} & \text { Strong } & \text { Strong } & \text { Weak } & \text { Weak } & \text { Weak } \\ & & & & & \\ & & & & & \\ \begin{array}{c}\text { Bowen } \\ \text { et al. } \\ (2012)^{[10]}\end{array} & & & & & \\ \end{array}$

Carter et al. Weak Strong Weak Weak Moderate
$(2007)$

Cheadle Weak Strong Strong Strong Weak
et al.
(1995)

Dixon et al. Moderate Strong Strong Weak Moderate
(2007)

$\begin{aligned} & \text { Donovan Weak Moderate Strong Strong Strong } \\ & \text { et al. } \\ & (2015)\end{aligned}$

$\begin{aligned} & \text { Komro Moderate Strong Strong Strong Strong } \\ & \text { et al. }\end{aligned}$
(2017)

Kulis et al. Strong Moderate Weak Weak Strong
No measurement of program Community-level allocation Strong consistency; attrition rates and analysis; statistical were measured; no mention of other interventions influencing methods (mixed effects regression models) were appropriate. outcomes.

Consistency of the program was measured (log books and weekly meetings); not all participants attended every session; no mention of other interventions influencing outcomes.

Organisation-level allocation Weak and analysis; statistical methods (discrete-time survival analysis) were appropriate for risk of marijuana initiation at different ages.

High consistency of program Individual-level allocation facilitation as it is computer-based; participant program attendance was extremely low; outcomes may be influenced by other factors occurring at the camp.

Facilitators followed a program manual; attrition rates were measured; no mention of other interventions influencing outcomes.

No description of exposure to program or consistency in delivery; outcomes likely to be influenced by other interventions taking place at the same time in the community.

No description of exposure to program or consistency in delivery; attrition rates were measured; no mention of other interventions influencing outcomes.

No description of exposure to program or consistency in delivery; attrition rates were measured; no mention of other interventions influencing outcomes.

Facilitators followed a program manual; attrition rates were measured; measured implementation of unaffiliated alcohol prevention efforts in community.

Consistency of program implementation was not measured; participant program attendance was

\section{and analysis; statistical} methods ( $t$ tests, chi-square tests) were appropriate.

Organisation-level allocation Weak and analysis; statistical methods (general linear model) were appropriate.

Community-level allocation Weak and analysis; statistical methods (frequencies, percentages, logistic regressions) were appropriate.

Organisation-level allocation Moderate and analysis; statistical methods (growth curve modelling) were appropriate.

Organisation-level allocation Moderate and analysis; statistical methods (Friedman's two-way analysis of variance by ranks, Wilcoxon signed rank tests) were appropriate.

Community-level allocation Strong and analysis; statistical methods (linear probability models) were appropriate.

Organisation-level allocation Weak and analysis; statistical methods (frequencies, $t$ tests) were appropriate. 
Table 4 (continued)

\begin{tabular}{llllllll}
\hline $\begin{array}{l}\text { First author } \\
\text { (year) }\end{array}$ & $\begin{array}{l}\text { Selection } \\
\text { bias }\end{array}$ & $\begin{array}{l}\text { Study } \\
\text { design }\end{array}$ & Confounds $\begin{array}{l}\text { Data } \\
\text { collection } \\
\text { methods }\end{array}$ & $\begin{array}{l}\text { Withdrawal } \\
\text { and drop- } \\
\text { outs }\end{array}$ & Intervention integrity & Analysis & $\begin{array}{l}\text { Summary } \\
\text { rating }\end{array}$ \\
\hline
\end{tabular}

\begin{tabular}{|c|c|c|c|c|c|c|c|c|}
\hline & & & & & & $\begin{array}{l}\text { not measured; no mention } \\
\text { of other interventions } \\
\text { influencing outcomes. }\end{array}$ & & \\
\hline $\begin{array}{l}\text { Kulis et al. } \\
\text { (2016) }\end{array}$ & Moderate & Strong & Strong & Strong & Weak & $\begin{array}{l}\text { Research teams attended } \\
\text { several lessons to measure } \\
\text { quality of instruction and } \\
\text { fidelity to the curriculum } \\
\text { manuals; participant } \\
\text { program attendance was } \\
\text { not measured; no mention } \\
\text { of other interventions } \\
\text { influencing outcomes. }\end{array}$ & $\begin{array}{l}\text { Organisation-level allocation } \\
\text { and analysis; statistical } \\
\text { methods ( } t \text { tests, Cohen's } \\
d \text {, general linear models) } \\
\text { were appropriate. }\end{array}$ & Moderate \\
\hline $\begin{array}{l}\text { Lowe et al. } \\
\text { (2012) }\end{array}$ & Moderate & Strong & Strong & Strong & Strong & $\begin{array}{l}\text { Facilitators followed a } \\
\text { program manual; attrition } \\
\text { rates were measured; no } \\
\text { mention of other } \\
\text { interventions influencing } \\
\text { outcomes. }\end{array}$ & $\begin{array}{l}\text { Organisation-level allocation } \\
\text { and analysis; statistical } \\
\text { methods ( } t \text { tests, general } \\
\text { linear model) were } \\
\text { appropriate. }\end{array}$ & Strong \\
\hline $\begin{array}{l}\text { Moran } \\
\text { (1999) }\end{array}$ & Weak & Moderate & Strong & Strong & Strong & $\begin{array}{l}\text { No description of exposure } \\
\text { to program or consistency } \\
\text { in delivery; outcomes may } \\
\text { have been influenced by } \\
\text { other factors in the } \\
\text { community or school } \\
\text { setting (i.e. school } \\
\text { curriculum) }\end{array}$ & $\begin{array}{l}\text { Community-level allocation } \\
\text { and analysis; statistical } \\
\text { methods ( } t \text { tests) were } \\
\text { appropriate. }\end{array}$ & Moderate \\
\hline $\begin{array}{l}\text { Moran et al. } \\
\text { (2007) }\end{array}$ & Weak & Moderate & Strong & Strong & Weak & $\begin{array}{l}\text { No description of program } \\
\text { consistency; exposure to } \\
\text { program described; no } \\
\text { mention of other } \\
\text { interventions influencing } \\
\text { outcomes. }\end{array}$ & $\begin{array}{l}\text { Community-level allocation } \\
\text { and analysis; statistical } \\
\text { methods (frequencies, } \\
\text { ANOVA) were } \\
\text { appropriate. }\end{array}$ & Weak \\
\hline $\begin{array}{l}\text { Patchell } \\
\text { et al. } \\
(2015)\end{array}$ & Moderate & Moderate & Strong & Strong & Strong & $\begin{array}{l}\text { No measurement of program } \\
\text { consistency; participant } \\
\text { program attendance was } \\
\text { not measured; no mention } \\
\text { of other interventions } \\
\text { influencing outcomes. }\end{array}$ & $\begin{array}{l}\text { Community-level allocation } \\
\text { and analysis; statistical } \\
\text { methods (frequencies, } t \\
\text { tests) were appropriate. }\end{array}$ & Strong \\
\hline $\begin{array}{l}\text { Petoskey } \\
\text { et al. } \\
(1998)\end{array}$ & Moderate & Moderate & Strong & Strong & Weak & $\begin{array}{l}\text { Consistency of the program } \\
\text { was measured; unable to } \\
\text { measure participant } \\
\text { attendance due to } \\
\text { anonymous reporting; } \\
\text { outcomes may have been } \\
\text { influenced by other factors } \\
\text { resulting from varying } \\
\text { implementation sites. }\end{array}$ & $\begin{array}{l}\text { Organisation-level allocation } \\
\text { and analysis; statistical } \\
\text { methods (ANOVA, } \\
\text { correlations) were } \\
\text { appropriate. }\end{array}$ & Moderate \\
\hline $\begin{array}{l}\text { Schinke } \\
\text { et al. } \\
\text { (1994) }\end{array}$ & Moderate & Moderate & Weak & Weak & Weak & $\begin{array}{l}\text { High consistency of program } \\
\text { facilitation as it is } \\
\text { computer-based; unlikely } \\
\text { that other factors influence } \\
\text { outcomes as it is a } \\
\text { one-session program. }\end{array}$ & $\begin{array}{l}\text { Individual-level allocation } \\
\text { and analysis; statistical } \\
\text { methods (descriptives, } t \\
\text { tests) were appropriate. }\end{array}$ & Weak \\
\hline $\begin{array}{l}\text { Schinke } \\
\text { et al. } \\
(2000)\end{array}$ & Moderate & Moderate & Strong & Weak & Strong & $\begin{array}{l}\text { No description of } \\
\text { consistency in delivery; } \\
\text { attrition rates were } \\
\text { measured; a community } \\
\text { intervention was running } \\
\text { simultaneously, likely to } \\
\text { influence outcomes. }\end{array}$ & $\begin{array}{l}\text { Organisation-level allocation } \\
\text { and analysis; statistical } \\
\text { methods (ANOVA) were } \\
\text { appropriate. }\end{array}$ & Moderate \\
\hline
\end{tabular}


Table 4 (continued)

\begin{tabular}{|c|c|c|c|c|c|c|c|c|}
\hline $\begin{array}{l}\text { First author } \\
\text { (year) }\end{array}$ & $\begin{array}{l}\text { Selection } \\
\text { bias }\end{array}$ & $\begin{array}{l}\text { Study } \\
\text { design }\end{array}$ & Confounds & $\begin{array}{l}\text { Data } \\
\text { collection } \\
\text { methods }\end{array}$ & $\begin{array}{l}\text { Withdrawal } \\
\text { and drop- } \\
\text { outs }\end{array}$ & Intervention integrity & Analysis & $\begin{array}{l}\text { Summary } \\
\text { rating }\end{array}$ \\
\hline $\begin{array}{l}\text { Usera } \\
\qquad(2017)\end{array}$ & Moderate & Moderate & Strong & Moderate & Moderate & $\begin{array}{l}\text { Consistency of the program } \\
\text { was measured (log books, } \\
\text { observation logs); attrition } \\
\text { rates were measured; no } \\
\text { mention of other }\end{array}$ & $\begin{array}{l}\text { Community-level allocation } \\
\text { and analysis; statistical } \\
\text { methods (MANOVA, } \\
\text { ANOVA) were } \\
\text { appropriate. }\end{array}$ & Strong \\
\hline
\end{tabular}

Australia
$\begin{gathered}\text { Gray et al. Weak Moderate Weak Weak Weak } \\ (1998)\end{gathered}$

interventions influencing outcomes.

No description of participant attendance; program consistency is unlikely as new program strategies were employed across the 2 years; no mention of other interventions influencing outcomes.

$\begin{array}{lllll}\begin{array}{l}\text { Howard } \\ \text { et al. }\end{array} & \text { Weak } & \text { Moderate Strong } & \text { Weak } & \text { Weak } \\ (2012) & & & & \\ & & & & \\ & & & & \\ \begin{array}{c}\text { Johnston } \\ \text { et al. }\end{array} & \text { Moderate } & \text { Moderate Strong } & \text { Weak } & \text { Weak } \\ (1998) & & & & \end{array}$

Lee et a Weak Moderate Weak (2008)

Malseed Moderate Moderate Weak

Weak

Weak

et al.

Sheehan Weak Moderate Weak (1995)
Weak Moderate

Moderate

No measurement of program program attendance was not measured; no mention of other interventions influencing outcomes.

Consistency of the program was not measured; not all participants attended every session; outcomes of the multi-component school and community program may have been influenced by other factors (i.e. tobacco education as part of the school curriculum).

Many youth involved in the interventions, no information on consistency, outcomes likely to be influenced by other interventions taking place at the same time in the community (including stricter supply controls and rewards linked to school attendance).

No program consistency in delivery; no measure of participant sample size; no mention of other interventions influencing outcomes.

No description of consistency in delivery; high absentee rates for each lesson; outcomes likely to be influenced by other interventions taking consistency; participant
Organisation-level allocation Weak and analysis; comparability of results was compromised by four factors: different survey questions, different points on the response scales, different levels of supervision and data was not systematically collected; no statistical analyses were conducted.

Community-level allocation; Weak no statistical analysis (outcomes as percentages only).

Organisation-level allocation Weak and analysis; minority of participants completed both surveys making statistical calculations inappropriate for comparisons.

Community-level allocation Weak and analysis; statistical methods described in other publication. Dates of data collection (2001-2004) do not line up with dates of intervention (2003-2005), no post-test data.

Organisation-level allocation Weak and analysis; statistical methods (linear and logistic mixed-effects regression) were appropriate.

Organisation-level allocation Weak and analysis; one-quarter of participants were included in analysis due to irregular attendance rate; no statistical analysis 
Table 4 (continued)

\begin{tabular}{|c|c|c|c|c|c|c|c|c|}
\hline $\begin{array}{l}\text { First author } \\
\text { (year) }\end{array}$ & $\begin{array}{l}\text { Selection } \\
\text { bias }\end{array}$ & $\begin{array}{l}\text { Study } \\
\text { design }\end{array}$ & Confounds & $\begin{array}{l}\text { Data } \\
\text { collection } \\
\text { methods }\end{array}$ & $\begin{array}{l}\text { Withdrawal } \\
\text { and drop- } \\
\text { outs }\end{array}$ & Intervention integrity & Analysis & $\begin{array}{l}\text { Summary } \\
\text { rating }\end{array}$ \\
\hline & & & & & & $\begin{array}{l}\text { place at the same time in } \\
\text { the community. }\end{array}$ & $\begin{array}{l}\text { (outcomes as percentages } \\
\text { only). }\end{array}$ & \\
\hline \multicolumn{9}{|l|}{ Canada } \\
\hline $\begin{array}{l}\text { Baydala } \\
\text { et al. } \\
(2014)^{[11]}\end{array}$ & Moderate & Moderate & Strong & Weak & Moderate & $\begin{array}{l}\text { Consistency of the program } \\
\text { was measured; not all } \\
\text { participants attended } \\
\text { every session; no mention } \\
\text { of other interventions } \\
\text { influencing outcomes. }\end{array}$ & $\begin{array}{l}\text { Organisation-level allocation } \\
\text { and analysis; statistical } \\
\text { methods (ANOVA, } \\
\text { correlations) were } \\
\text { appropriate; thematic } \\
\text { analysis of qualitative data } \\
\text { was appropriate. }\end{array}$ & Moderate \\
\hline $\begin{array}{l}\text { Mushquash } \\
\text { et al. } \\
(2007)^{[12]}\end{array}$ & Weak & Moderate & Weak & Strong & Moderate & $\begin{array}{l}\text { Consistency of the program } \\
\text { was measured; no mention } \\
\text { of other interventions } \\
\text { influencing outcomes. }\end{array}$ & $\begin{array}{l}\text { Organisation-level allocation } \\
\text { and analysis; statistical } \\
\text { methods not described. }\end{array}$ & Weak \\
\hline
\end{tabular}

Table 5 Search strategy MEDLINE

1 ((substance OR drug OR alcohol OR tobacco OR petrol OR cannabis OR kava OR methamphetamine OR MDMA OR inhalant OR marijuana OR amphetamine OR "psycho stimulant" OR smok* OR "illicit drug” OR "volatile drug”) AND (evaluat* OR effect* OR efficacy OR review OR trial) AND ((Indigenous OR Aborigin* OR "Torres Strait*" OR Maor* OR "First Nation" OR Inuit OR "American Indian*" OR "Alaskan Indian*”) AND (Austral* OR "New Zealand*” OR Canad* OR Americ*)) AND (youth OR young OR adolescen* OR teen*)).mp. AND (educat* OR prevent* OR interven* OR program).m_titl.

2 limit 1 to $\mathrm{yr}=$ "1990-2017"

$[\mathrm{mp}=$ title, abstract, original title, name of substance word, subject heading word, keyword heading word, protocol supplementary concept word, rare disease supplementary concept word, unique identifier]

Funding Information This study was funded by the Australian Government Department of Health. Dr. Stapinski receives a Translating Research Into Practice (TRIP) Fellowship from the National Health and Medical Research.

\section{Compliance with Ethical Standards}

Conflict of Interest The authors declare that they have no competing interests.

Ethical Approval and Informed Consent As this study manuscript describes a literature review, there was no ethical approval nor informed consent.

Open Access This article is distributed under the terms of the Creative Commons Attribution 4.0 International License (http:// creativecommons.org/licenses/by/4.0/), which permits unrestricted use, distribution, and reproduction in any medium, provided you give appropriate credit to the original author(s) and the source, provide a link to the Creative Commons license, and indicate if changes were made.

\section{References}

Allen, J., Rasmus, S. M., Fok, C. C. T., Charles, B., \& Henry, D. (2017). Multi-level cultural intervention for the prevention of suicide and alcohol use risk with alaska native youth: A nonrandomized comparison of treatment intensity. Prevention Science(Pagination). doi: https://doi.org/10.1007/s11121-017-0798-9

Asdigian, N. L., Whitesell, N. R., Keane, E. M., Mousseau, A. C., \& Kaufman, C. E. (2016). Effects of the "Circle of Life" HIVprevention program on marijuana use among American Indian middle school youths: a group randomized trial in a Northern Plains tribe. The American Journal of Drug and Alcohol Abuse, 1-9. doi: https://doi.org/10.1080/00952990.2016.1265122

Australian Government. (2013). National Aboriginal and Torres Strait Islander Health Plan 2013-2023. Canberra: Commonwealth of Australia.

Australian Institute of Health and Welfare. (2006). Drug use among Aboriginal and Torres Strait Islander peoples: An assessment of data sources. Canberra: AIHW.

Barry, M. M., Clarke, A. M., Jenkins, R., \& Patel, V. (2013). A systematic review of the effectiveness of mental health promotion interventions for young people in low and middle income countries. BMC Public Health, 13, 835. https://doi.org/10.1186/1471-2458-13-835.

Baydala, L., Fletcher, F., Worrell, S., Kajner, T., Letendre, S., Letendre, L., \& Rasmussen, C. (2014). Partnership, knowledge translation, and substance abuse prevention with a First Nations community. Progress in Community Health Partnerships, 8, 145-155.

Beauvais, F. (1992). Comparison of drug use rates for reservation Indian, non-reservation Indian and Anglo youth. American Indian and Alaska Native Mental Health Research, 5, 1992.

Behrendt, S., Wittchen, H.-U., Höfler, M., Lieb, R., \& Beesdo, K. (2009). Transitions from first substance use to substance use disorders in adolescence: Is early onset associated with a rapid escalation? Drug and Alcohol Dependence, 99, 68-78. 
Belone, L., Oetzel, J. G., Wallerstein, N., Tafoya, G., Rae, R., Rafelito, A., \& Thomas, A. (2012). Using participatory research to address substance abuse in an American-Indian community. Communication activism, 3, 403-434.

Belone, L., Orosco, A., Damon, E., Smith-McNeal, W., Rae, R., Sherpa, M. L., Myers, O. B., Omeh, A. O., \& Wallerstein, N. (2017). The piloting of a culturally centered American Indian family prevention program: a CBPR partnership between Mescalero Apache and the University of New Mexico. Public Health Reviews, 38, 30. https:// doi.org/10.1186/s40985-017-0076-1.

Bowen, D., Henderson, P., Harvill, J., \& Buchwald, D. (2012). Short-term effects of a smoking prevention website in American Indian youth. Journal of medical Internet research, 14, e81. Retrieved from. https://doi.org/10.2196/jmir.1682.

Bryant, J., Ward, J., Wand, H., Byron, K., Bamblett, A., Waples-Crowe, P., Betts, S., Coburn, T., Delaney-Thiele, D., Worth, H., Kaldor, J., \& Pitts, M. (2016). Illicit and injecting drug use among Indigenous young people in urban, regional and remote Australia. Drug and Alcohol Review, 35, 447-455. https://doi.org/10.1111/dar.12320.

Bureau of Indian Education. (2017). Schools. September 2017 Retrieved from https://www.bie.edu/Schools/index.htm

Calabria, B., Clifford, A., Shakeshaft, A., \& Doran, C. (2012). A systematic review of family-based interventions targeting alcohol misuse and their potential to reduce alcohol-related harm in indigenous communities. Journal of Studies on Alcohol and Drugs, 73, 477-488.

Carter, S. L., Straits, J. E., \& Hall, M. (2007). Project venture: Evaluation of a positive, culture-based approach to substance abuse prevention with American Indian youth. Technical Report. The National Indian Youth Leadership Project. Gallup, NM.

Castro, F. G., \& Yasui, M. (2017). Advances in EBI development for diverse populations: Towards a science of intervention adaptation. Prevention Science, 18, 623-629. https://doi.org/10.1007/s11121-017-0809-x.

Centers for Disease Control and Prevention. (2018). United States High School Youth Risk Behavior Survey 2017.

Champion, K. E., Newton, N. C., \& Teesson, M. (2016). Prevention of alcohol and other drug use and related harm in the digital age: What does the evidence tell us? Current Opinion in Psychiatry, 29, 242-249.

Cheadle, A., Pearson, D., Wagner, E., Psaty, B. M., Diehr, P., \& Koepsell, T. (1995). A community-based approach to preventing alcohol use among adolescents on an American Indian reservation. Public Health Reports, 110, 439-447.

Chikritzhs, T., \& Brady, M. (2006). Fact or fiction? a critique of the National Aboriginal and Torres Strait Islander Social Survey 2002. Drug and Alcohol Review, 25, 277-287.

Chou, W.-y. S., Prestin, A., Lyons, C., \& Wen, K.-y. (2013). Web 2.0 for health promotion: Reviewing the current evidence. American Journal of Public Health, 103, e9-e18. https://doi.org/10.2105/ajph.2012.301071.

Clifford, A., \& Shakeshaft, A. (2017). A bibliometric review of drug and alcohol research focused on Indigenous peoples of Australia, New Zealand, Canada and the United States. Drug and Alcohol Review. https://doi.org/10.1111/dar.12510.

Clifford, A., Pulver, L. J., Richmond, R., Shakeshaft, A., \& Ivers, R. (2011). Smoking, nutrition, alcohol and physical activity interventions targeting Indigenous Australians: Rigorous evaluations and new directions needed. Australian and New Zealand Journal of Public Health, 35, 38-46.

Coalition of Australian Governments. (2009). Closing the gap on Indigenous Disadvantage: The challenge for Australia. Retrieved from Canberra.

Cochran, P. A., Marshall, C. A., Garcia-Downing, C., Kendall, E., Cook, D., McCubbin, L., \& Gover, R. M. S. (2008). Indigenous ways of knowing: Implications for participatory research and community. American Journal of Public Health, 98, 22-27.

Cornell, S. E. (2006). Indigenous peoples, poverty and self-determination in Australia, New Zealand, Canada and the United States. Tuscon: Native Nations Institute for Leadership, Management, and Policy.

Degenhardt, L., Stockings, E., Patton, G., Hall, W. D., \& Lynskey, M. (2016). The increasing global health priority of substance use in young people. The Lancet Psychiatry, 3, 251-264. https://doi.org/ 10.1016/S2215-0366(15)00508-8.

Dickerson, D., Baldwin, J. A., Belcourt, A., Belone, L., Gittelsohn, J., Kaholokula, J. K. A., Lowe, J., Patten, C. A., \& Wallerstein, N. (2018). Encompassing cultural contexts within scientific research methodologies in the development of health promotion interventions. Prevention Science, 1-10.

Dixon, A. L., Yabiku, S. T., Okamoto, S. K., Tann, S. S., Marsiglia, F. F., Kulis, S., \& Burke, A. M. (2007). The efficacy of a multicultural prevention intervention among urban American Indian youth in the southwest U.S. Journal of Primary Prevention, 28, 547-568.

Donovan, D. M., Thomas, L. R., Sigo, R. L. W., Price, L., Lonczak, H., Lawrence, N., Ahvakana, K., Austin, L., Lawrence, A., Price, J., Purser, A., \& Bagley, L. (2015). Healing of the Canoe: Preliminary results of a culturally grounded intervention to prevent substance abuse and promote tribal identity for Native youth in two Pacific Northwest tribe. American Indian and Alaska Native Mental Health Research, 22, 42-76.

Doran, C., Kinchin, I., Bainbridge, R., McCalman, J., \& Shakeshaft, A. (2017). Effectiveness of alcohol and other drug interventions in at-risk Aboriginal youth: an evidence check rapid review brokered by the Sax Institute for the NSW Ministry of Health. Retrieved from Sydney.

Foxcroft, D. R., \& Tsertsvadze, A. (2012). Universal alcohol misuse prevention programmes for children and adolescents: Cochrane systematic reviews. Perspectives in Public Health, 132, 128-134.

Garakani, T. (2014). Young people have a lot to say... with trust, time, and tools: The voices of Inuit youth in Nunavik. Canadian Journal of Education/Revue canadienne de l'éducation, 37(1).

Grant, B. F., Stinson, F. S., \& Harford, T. C. (2001). Age at onset of alcohol use and DSM-IV alcohol abuse and dependence: a 12-year follow-up. Journal of Substance Abuse, 13, 493-504.

Gray, D., Sputore, B., \& Walker, J. (1998). Evaluation of an Aboriginal Health Promotion Program: A case study from Karalundi. Health Promotion Journal of Australia, 8, 24-28.

Hecht, M. L., Marsiglia, F. F., Elek, E., Wagstaff, D. A., Kulis, S., Dustman, P., \& Miller-Day, M. (2003). Culturally grounded substance use prevention: An evaluation of the keepin'it REAL curriculum. Prevention Science, 4, 233-248.

Howard, J., Alperstein, D., \& Smith, O. (2012). Young men and yarndi: A pilot to diffuse informaion in cannabis, its use and potential risks among young Aboriginal and Torres Strait Islander Australians. National cannabis prevention and information centre bulletin, Series, $15,1-22$.

Johnston, V., \& Thomas, D. P. (2008). Smoking behaviours in a remote Australian indigenous community: The influence of family and other factors. Social Science \& Medicine, 67, 1708-1716. https://doi. org/10.1016/j.socscimed.2008.09.016.

Johnston, F., Beecham, R., Dalgleish, P., Malpraburr, T., \& Gamarania, G. (1998). The Maningrida 'Be smoke free' project. Health Promotion Journal of Australia, 8, 12-17.

King, M., Smith, A., \& Gracey, M. (2009). Indigenous health part 2: The underlying causes of the health gap. The Lancet, 374, 76-85. https:// doi.org/10.1016/S0140-6736(09)60827-8.

Kirmayer, L., Simpson, C., \& Cargo, M. (2003). Healing traditions: Culture, community and mental health promotion with Canadian Aboriginal peoples. Australasian Psychiatry, 11, S15-S23. https:// doi.org/10.1046/j.1038-5282.2003.02010.x.

Komro, K., Livingston, M., Wagenaar, A., Kominsky, T., Pettigrew, D., \& Garrett, B. (2017). Multilevel prevention trial of alcohol use among American Indian and white high school students in the Cherokee nation. American journal of public health, 107, 453-459. Retrieved from. https://doi.org/10.2105/AJPH.2016.303603.

Kulis, S., Dustman, P. A., Brown, E. F., \& Martinez, M. (2013). Expanding urban American Indian youths' repertoire of drug resistance skills: Pilot results from a culturally adapted prevention 
program. American Indian and Alaska Native Mental Health Research, 20, 35-54.

Kulis, S. S., Ayers, S. L., \& Harthun, M. L. (2016). Substance use prevention for urban American Indian youth: A efficacy trial of the culturally adapted living in 2 worlds program. The journal of primary prevention.

Kumpfer, K. L., Whiteside, H. O., Greene, J. A., \& Allen, K. C. (2010). Effectiveness outcomes of four age versions of the Strengthening Families Program in statewide field sites. Group Dynamics: Theory, Research, and Practice, 14, 211-229.

Kunitz, S. J. (2008). Risk factors for polydrug use in a Native American population. Substance Use \& Misuse, 43, 331-339. https://doi.org/ 10.1080/10826080701202783.

Lee, K., Conigrave, K. M., Clough, A. R., Wallace, C., Silins, E., \& Rawles, J. (2008). Evaluation of a community-driven preventive youth initiative in Arnhem Land, Northern Territory, Australia. Drug and Alcohol Review, 27, 75-82.

Lee, K. K., Jagtenberg, M., Ellis, C. M., \& Conigrave, K. M. (2013). Pressing need for more evidence to guide efforts to address substance use among young Indigenous Australians. Health Promotion Journal of Australia, 24.

Lee, N. K., Cameron, J., Battams, S., \& Roche, A. (2016). What works in school-based alcohol education: A systematic review. Health Education Journal, 75, 780-798.

Lee, K. K., Wilson, S., Perry, J., Room, R., Callinan, S., Assan, R., Hayman, N., Chikritzhs, T., Gray, D., Wilkes, E., Jack, P., \& Conigrave, K. M. (2018). Developing a tablet computer-based application ('App') to measure self-reported alcohol consumption in Indigenous Australians. BMC Medical Informatics and Decision Making, 18,8 .

Leske, S., Harris, M. G., Charlson, F. J., Ferrari, A. J., Baxter, A. J., Logan, J. M., Toombs, M., \& Whiteford, H. (2016). Systematic review of interventions for Indigenous adults with mental and substance use disorders in Australia, Canada, New Zealand and the United States. Australian and New Zealand Journal of Psychiatry, $50,1040-1054$

Long, A. F., \& Godfrey, M. (2004). An evaluation tool to assess the quality of qualitative research studies. International Journal of Social Research Methodology, 7, 181-196.

Lowe, J. A., Liang, H., Riggs, C., \& Henson, J. (2012). Community partnership to affect substance abuse among Native American Adolescents. American Journal of Drug and Alcohol Abuse, 38, $450-455$.

Malseed, C., Nelson, A., \& Ware, R. (2014). Evaluation of a school-based health education program for urban Indigenous young people in Australia. Health, 6, 587-597.

McNair Ingenuity Research. (2014). Media usage amongst Aboriginal and Torres Strait Islander People. Retrieved from Crows Nest.

Ministry of Health. (2015). Tatau Kahukura: Maori Health Chart Book $20153 r d$ edition. Wellington: Ministry of Health.

Moher, D., Liberati, A., Tetzlaff, J., \& Altman, D. G. (2009). Preferred reporting items for systematic reviews and meta-analyses: The PRISMA statement. Annals of Internal Medicine, 151, 264-269. https://doi.org/10.7326/0003-4819-151-4-200908180-00135.

Moran, J. R. (1999). Preventing alcohol use among urban American Indian youth: The seventh generation program. Journal of Human Behavior in the Social Environment, 2, 51-67.

Moran, J. R., \& Bussey, M. (2007). Results of an alcohol prevention program with urban American Indian youth. Child \& Adolescent Social Work Journal, 24, 1-21.

Mushquash, C. J., \& Bova, D. L. (2007). Cross-cultural assessment and measurement issues. Journal on Developmental Disabilities, 13, 53-65.

Mushquash, C. J., Comeau, N., \& Stewart, S. H. (2007). An alcohol abuse early intervention approach with Mi'kmaq adolescents. First Peoples Child \& Family Review, 3, 17-26.
Newton, N., Deady, M., \& Teesson, T. (2014). Alcohol and substance use prevention and early intervention. In P. B. A. A. Rosen (Ed.), Early intervention in psychiatry: EI of nearly everything for better mental health. New Jersey: John Wiley \& Sons, ltd..

Newton, N. C., Champion, K. E., Slade, T., Chapman, C., Stapinski, L., Koning, I., Tonks, Z., \& Teesson, M. (2017). A systematic review of combined student-and parent-based programs to prevent alcohol and other drug use among adolescents. Drug and Alcohol Review, 36, 337-351. https://doi.org/10.1097/YCO.0000000000000258.

Patchell, B. A., Robbins, L. K., Lowe, J. A., \& Hoke, M. M. (2015). The Effect of a Culturally Tailored Substance Abuse Prevention Intervention with Plains Indian Adolescents. Journal of Cultural Diversity, 22, 3-8.

Petoskey, E. L., Van Stelle, K. R., \& De Jong, J. A. (1998). Prevention through empowerment in a native American community. Drugs and Society, 12, 147-162.

Reading, C. L., \& Wien, F. (2009). Health inequalities and social determinants of Aboriginal peoples' health. Retrieved from Prince George, BC: http://epub.sub.uni-hamburg.de/epub/volltexte/2009/ 3060/pdf/NCCAH_Loppie_Wien_Report.pdf

Rice, E. S., Haynes, E., Royce, P., \& Thompson, S. C. (2016). Social media and digital technology use among indigenous young people in Australia: A literature review. International Journal for Equity in Health, 15. https://doi.org/10.1186/s12939-016-0366-0.

Schinke, S. P., Moncher, M. S., \& Singer, B. R. (1994). Native American youths and cancer risk reduction: Effects of software intervention. Journal of Adolescent Health, 15, 105-110.

Schinke, S. P., Tepavac, L., \& Cole, K. C. (2000). Preventing substance use among Native American youth: Three-year results. Addictive Behaviors, 25, 387-397.

Schnarch, B. (2004). Ownership, control, access, and possession (OCAP) or self-determination applied to research: A critical analysis of contemporary First Nations research and some options for First Nations communities. International Journal of Indigenous Health, 1, 80.

Sheehan, M., Schonfeld, C., Hindson, E., \& Ballard, R. (1995). Alcohol Education in an Indigenous Community School in Queensland, Australia. Drugs: education, prevention and policy, 2, 259-273. https://doi.org/10.3109/09687639509035749.

Smith, L. T. (2012). Decolonizing methodologies: Research and Indigenous Peoples (Vol. 2). London: Zed Books.

Snijder, M., Shakeshaft, A., Wagemakers, A., Stephens, A., \& Calabria, B. (2015). A systematic review of studies evaluating Australian indigenous community development projects: The extent of community participation, their methodological quality and their outcomes. BMC Public Health, 15, 1-16.

Snijder, M., Stapinski, L., Lees, B., Newton, N., Champion, K., Champman, C., Ward, J., \& Teeson, M. (2018). Substance use prevention programs for Indigenous adolescents in the United States of America, Canada, Australia and New Zealand: Protocol for a systematic review. JMIR Research Protocols, 7(2).

Templeton, L., Velleman, R., \& Russell, C. (2010). Psychological interventions with families of alcohol misusers: A systematic review. Addiction Research \& Theory, 18, 616-648.

Thomas, B. H., Ciliska, D., Dobbins, M., \& Micucci, S. (2004). A process for systematically reviewing the literature: Providing the research evidence for public health nursing interventions. Worldviews Evidence-Based Nursing, 1, 176-184.

Truth and Reconcilitation Commission. (2015). Honouring the truth, reconciling for the future: Summary of the Final Report of the Truth and Reconciliation Commission of Canada. Retrieved from Winnipeg.

United Nations. (2006). Who are Indigenous Peoples? Factsheet. Retrieved from New York.

United Nations. (2008). United Nations Declaration on the rights of Indigenous Peoples. Retrieved from New York.

Usera, J. J. (2017). The efficacy of an American Indian culturally-based risk prevention program for upper elementary school youth residing 
on the northern plains reservations. The journal of primary prevention, 38, 175-194. https://doi.org/10.1007/s10935-016-0462-3.

Whitesell, N. R., Beals, J., Mitchell, C. M., Manson, S. M., Turner, R. J., \& Team, A.-S. (2009). Childhood exposure to adversity and risk of substance-use disorder in two American Indian populations: The meditational role of early substance-use initiation. Journal of Studies on Alcohol and Drugs, 70, 971-981.

Windle, M., Spear, L. P., Fuligni, A. J., Angold, A., Brown, J. D., Pine, D., Smith, G. T., Giedd, J., \& Dahl, R. E. (2008). Transitions into underage and problem drinking: Developmental processes and mechanisms between 10 and 15 years of age. Pediatrics, 121, S273-S289.

Publisher's Note Springer Nature remains neutral with regard to jurisdictional claims in published maps and institutional affiliations. 